\title{
THE SEISMIC BEHAVIOUR OF TUNNELS IN LIQUEFACTION SOIL: A NUMERICAL STUDY
}

\author{
Ahmed O. Mahmoud ${ }^{a \& b^{*}}$ and Mamdouh A. Kenawi ${ }^{\mathrm{b}}$ \\ ${ }^{a}$ Civil engineering department - Sherbrooke University, Sherbrooke, Québec, J1K 2R1, Canada \\ ${ }^{b}$ Civil engineering department - Faculty of Engineering, Sohag University, 82524, Sohag, Egypt
}

\begin{abstract}
Underground structures can be severely damaged during strong earthquakes. Potential damage to infrastructure due to uplift increases in liquefied soils. Several models can be used to simulate soil liquefaction. This study presents a new numerical method to estimate the overall response of shallow-buried tunnels and to interpret the liquefaction mechanism in saturated sand around the structure under seismic action. The new method stems from the energy-based concept that can be used to compute the excess pore water pressure $\left(r_{u}\right)$ and turn it into external forces that would cause the uplift of the underground structure. This study uses a comparative numerical study of implementing the computer code, FLAC on the seismic performance of underground structures using this energy-based approach procedure to estimate pore pressure built-up and evaluate the underground structures' uplift. Moreover, the proposed pore water pressure model is validated against welldocumented laboratory data. Also, several study parameters have been considered to investigate the seismic behavior of tunnels.
\end{abstract}

(C) 2021 Published by Faculty of Engineering - Sohag University. DOI: 10.21608/SEJ.2021.155856.

Keywords: Tunnel; Liquefaction; Energy model; Excess pore water pressure; Uplift.

\section{INTRODUCTION}

Geotechnical structures buried near the ground surface have a wide range of applications, from small-scale pipelines such as means of gas transmission, telecommunications, water supply, and sewerage pipelines, to largescale infrastructures including tunnels for various transportation systems. These structures are becoming more and more prevalent in the modern world because of the decreasing availability of ground space due to the fastgrowing population [1]. In other words, underground infrastructures, serving for transport (e.g., highway tunnels and subway metro), utility (e.g., gas and water pipelines) and storage purposes (e.g., fuel storage and water tanks) have been a widespread alternative to what in redeveloping urban spaces to ease land congestion pressures. However, in the event of an earthquake, the functionality of these structures could be put at risk especially when they were constructed in potentially liquefied soils [2]. The uplift phenomenon of buried structures has been abundantly reported following several earthquakes. Many other earthquakes (e.g., the 2004 Niigata Chuetsu, the 2007 Noto Hanto, and the 2007 Niigata Chuetsu-oki) caused serious damage to buried structures in the form of uplifting manholes and settlement of pavement above backfill soil for pipes [3]. For example, during the 2004 earthquake in Niigata-ken Chuetsu, Japan, more than 1400 manholes were uplifted causing serious lifeline problems. The Haiti 2010 Earthquake resulted in severe destruction of essential systems (e.g., transportation and

* Corresponding author: Ahmed.Mahmoud@USherbrooke.ca 
lifeline systems) leading to a $60 \%$ loss of the nation's infrastructure [4]. Also, substantial damage to buildings and underground structures has been reported after the magnitude 7.1 earthquake and its aftershocks in Christchurch's central city and eastern suburbs [5].

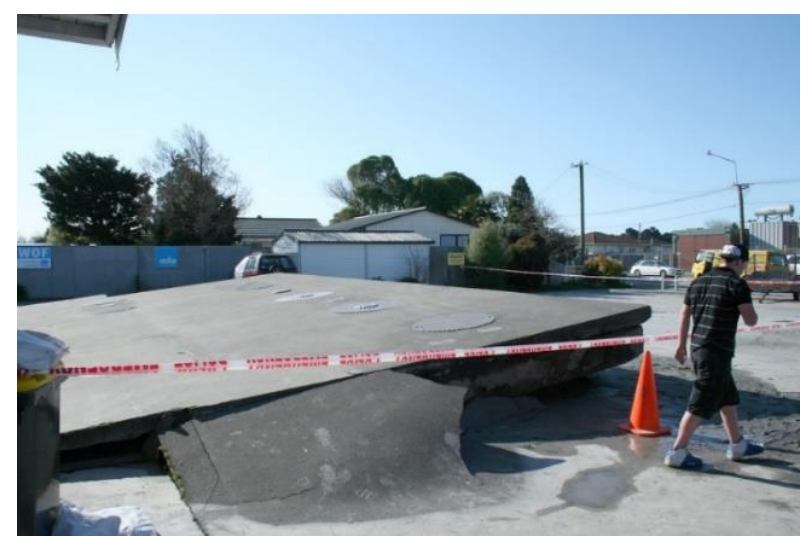

Fig. 1. Petrol tank uplift - Christchurch Earthquake [6].

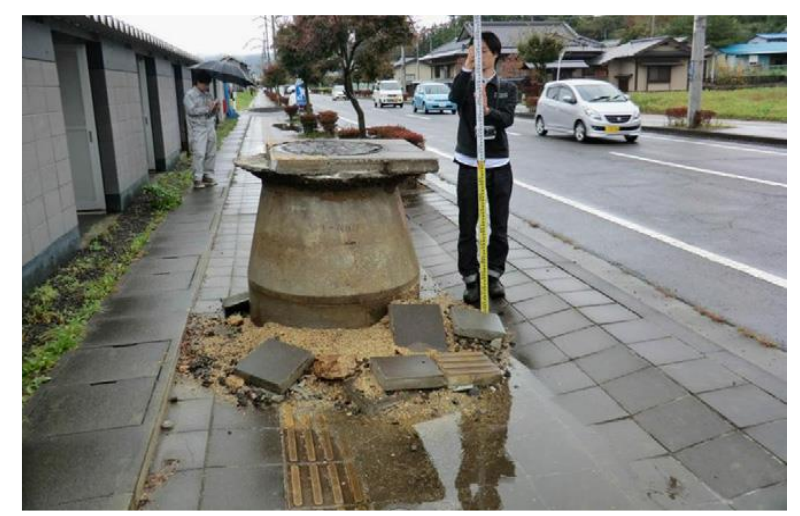

Fig. 2. Uplift of a manhole - Tohoku Earthquake [7].

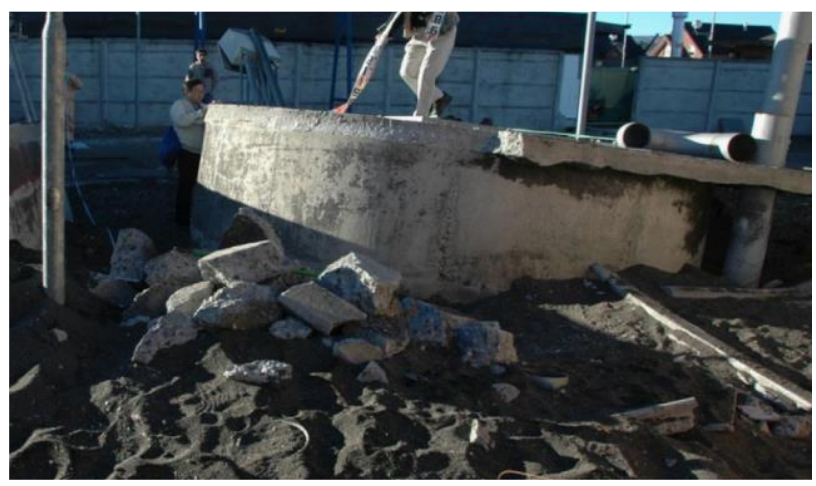

Fig. 3. Uplifted sewage tank - 2010 Chile Earthquake [8].

Some examples of underground structures uplift during major earthquakes are shown in Fig. 1. The figure shows some liquefaction effects on infrastructure (i.e., uplift of the petrol tank) at the Christchurch site [6]. Also, Fig. 2 shows the uplift of a manhole at West Takanosu, Shiraishi City, which uplifted to $1.15 \mathrm{~m}$. Since the ground subsided along the sewage line, fill at the construction of the sewage line is supposed to have liquefied [7]. In the 2010 Maule Earthquake, in Chile, the uplifting of the underground structures (manholes and underground 
tanks) was reported, and the underground tank in San Pedrodel Valle was uplifted by approximately $1.2 \mathrm{~m}$, as shown in Fig. 3 [8].

Different methods could represent the soil liquefaction process that is has become popular among practicing engineers. Beginning the screening criteria method which can determine the possibility of liquefaction occurring. Then empirical methods and simplified methods which used to evaluate soil liquefaction potential. These methods use deterministic relations to develop bounds or boundary curves to imply the occurrence of liquefaction and the safety against. Moreover, with the complexity of the problems, various analytical and numerical methods have been developed to estimate liquefaction induced by earthquakes [9]. These methods are divided into three main estimation approaches to evaluate the soil liquefaction: (1) stress-based procedures, (2) strain-based procedures, and (3) energy-based procedures [10]. The models used will be summarized in the following.

In this paper, the study focused on the built-up pore water pressure and underground structure uplift due to soil liquefaction. The underground structure is a rectangular tunnel with shallow embedment depth. It is therefore important to understand both the seismic behavior of such tunnels and the uplift suffered by the tunnel sections under multiple earthquake motions, in soils of various stiffness, with different soil thickness and water table level, and with several structure depths.

\section{CONSTITUTIVE MODEL}

Several models have been developed an empirical, closed-form solution to calculate excess pore-water pressure ratio $\left(r_{u}\right)$ which is considered to the initial effective confining stress. Some examples of these constitutive models are based on the stresses list below.

\subsection{Energy-based model}

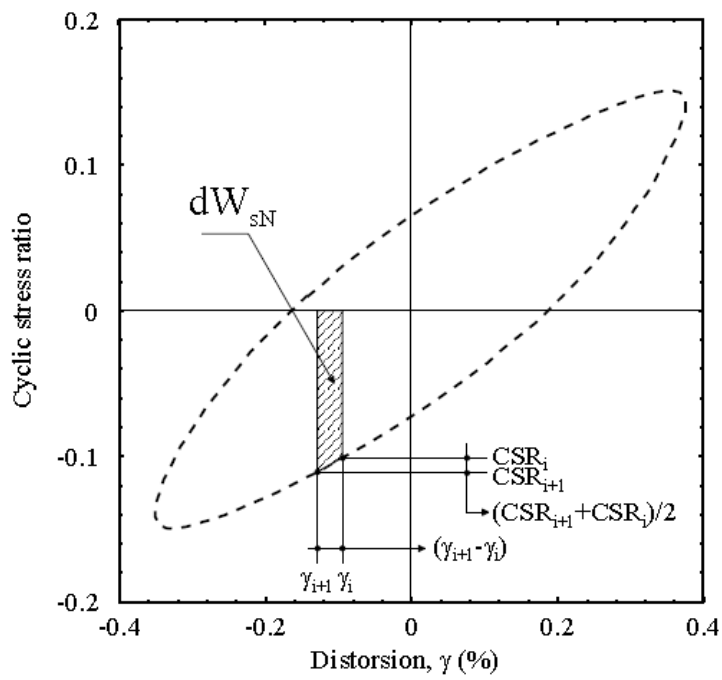

Fig. 4. Dissipated energy per unit volume of soil [13].

The energy-based approach generally uses the energy dissipated in the soil during cyclic loading to predict the change in the pore-water pressure developed in the soil [11]. Although energy-based methods have been successfully applied to laboratory data and field case studies [12], these methods have not been widely adopted in numerical modeling. Karray et al [13] used the energy-based approach to compute $r_{u}$ from the stress-strain hysteresis relationship as:

$$
r_{u}=\alpha\left(\frac{W_{s}^{0.5}}{a_{x}}\right)^{\beta}
$$

where $W_{s}$ is the energy dissipated per unit volume of soil divided by the initial effective confining pressure which can be determined by integrating area bound by stress-strain hysteresis loops (Fig. 4), $a_{x}$ is a variable parameter 
depend on soil type, $\alpha$, and $\beta$ are constant parameter depends on soil properties and can be determined from experimental tests using cyclic loading tests such as the $\mathrm{T}_{\mathrm{x}} \mathrm{SS}$ and Triaxial simple shear tests.

\section{NUMERICAL MODELING}

In this study, the finite difference (FD) computer code, FLAC has been implemented to simulate the seismic behavior of underground structures buried in liquefiable soils. Two soil constitutive models have been considered in this study; namely the energy-based model and the Finn model to simulate the build-up of pore water pressure. Ottawa sand is used in this study as a soil bed. Its coefficient of permeability and the void ratio was determined from typical laboratory tests and were found to $1 \times 10^{-5} \mathrm{~m} / \mathrm{s}$ and 0.44 , respectively. The dynamic characteristics of Ottawa sand were obtained from triaxial simple shear test $\left(\mathrm{T}_{\mathrm{x}} \mathrm{SS}\right)$ results.

The FD analyses were performed in two stages. In the first stage (static analysis), the in-situ stresses were initialized in the soil due to the own weight of the soil. The boundary between the soil deposit and the bedrock was assumed to be fixed in both horizontal and vertical directions and acted as the bottom boundary of the analyzed domain. However, the lateral boundaries are assumed to be fixed in horizontal directions only. The ground surface was assumed to be flat and free of loadings. As an extreme case, the underground water level is assumed to locate at the ground surface also, in the other cases is assumed to be under the ground surface. During the second stage of analysis (dynamic analysis), quiet (viscous) conditions are used to reduce wave reflections at model boundaries. Besides, the free field (FF) conditions are considered.

Hysteretic damping allows strain-dependent modulus and damping functions to be incorporated directly into the FLAC simulation. When using simple models, the choice is between Rayleigh damping constitutive and hysteretic damping. From some general comparisons between the two approaches, enabling a choice to be made. In general, hysteretic damping is more realistic than Rayleigh damping, and it entails no reduction in time-step. The hysteretic damping formulation is not a complete model, but it is used as a supplement to one of the built-in nonlinear models, and not as a primary way to simulate yielding. Rayleigh damping is not necessary when hysteretic damping is in operation, however, it was used (at low levels $=0.2 \%$ ) to remove high-frequency noise. In this paper, uniform velocities and earthquake accelerations were used as input motion [14].

\section{VALIDATION OF THE MODEL}

\begin{tabular}{lcc}
\multicolumn{2}{c}{ TABLE 1. CHARACTERISTICS OF THE TESTED SOILS } \\
\hline Properties & Hostun sand & Ottawa sand \\
\hline$\phi_{\text {crit }}\left({ }^{\circ}\right)$ & 33 & 30 \\
$\mathrm{D}_{10}(\mathrm{~mm})$ & 0.209 & 0.22 \\
$\mathrm{D}_{50}(\mathrm{~mm})$ & 0.335 & 0.4 \\
$\mathrm{e}_{\min }$ & 0.555 & 0.5 \\
$\mathrm{e}_{\max }$ & 1.01 & 0.82 \\
$\mathrm{G}_{\mathrm{s}}$ & 2.65 & 2.67 \\
\hline
\end{tabular}

Before applying the numerical model, the constitutive model was validated with previous experimental and numerical models. Chian et al. [15] carried out numerical modeling accompanied by centrifuge experiments with underground structure (circular tunnel) to study the increase of pore water pressure. The centrifuge experiments were created using a window box. The numerical modeling was performed adopting the Wang soil model using the computer code FLAC ${ }^{2 \mathrm{D}}$. The Wang model is a nonlinear, fully coupled bounding surface plasticity constitutive model for sand [16]. Hostun sand of relative density (45\%) was used in the physical and numerical models. The material properties of the sand used during the tests are described in Table 1. In the current analysis, the structure is assumed to be an elastic material with Young modulus and the Poisson ratio of $25 \mathrm{e} 9 \mathrm{~Pa}$ and 0.25 . The dimensions of the zone elements were selected to be equal to $0.5 \times 0.5 \mathrm{~m}$. A sin wave acceleration with amplitude $=2.2 \mathrm{~m} / \mathrm{s}^{2}$ and frequency $=0.75 \mathrm{~Hz}$ was applied as a seismic load. The groundwater table was assumed at the ground surface. 


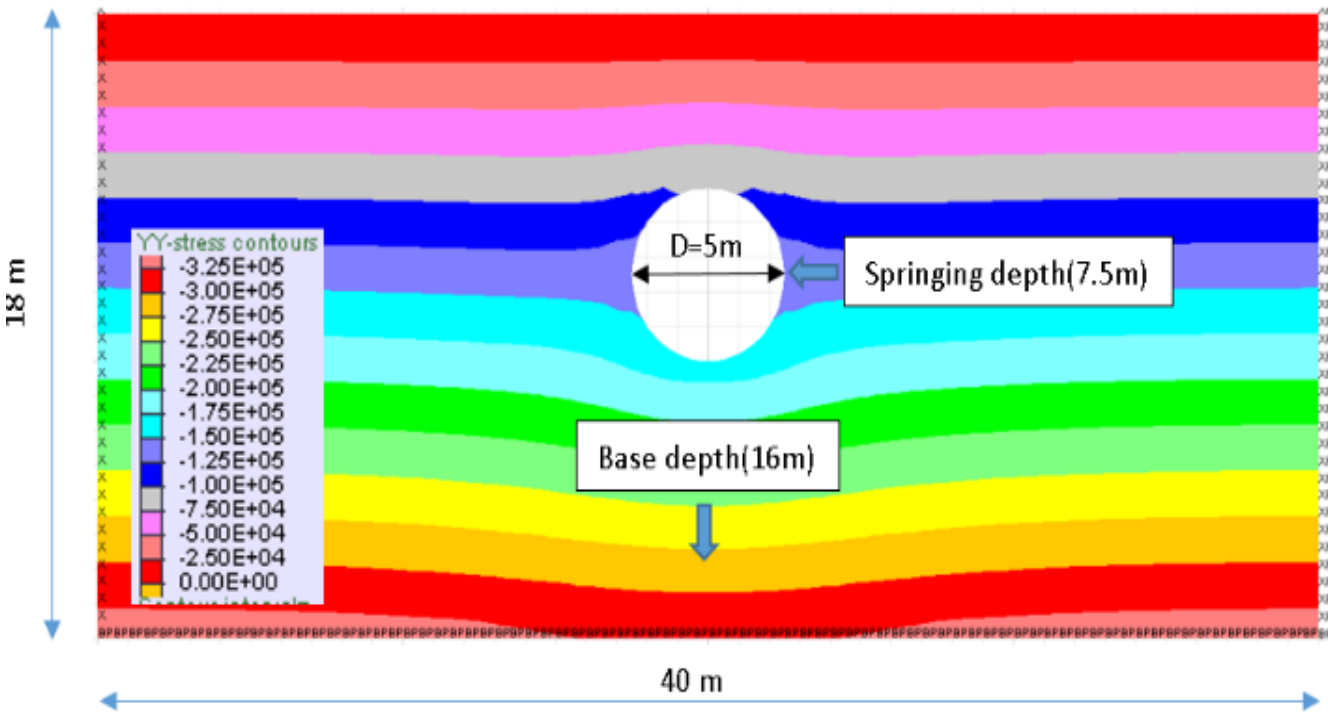

Fig. 5. The cross-sectional view of the tunnel model built by FLAC.

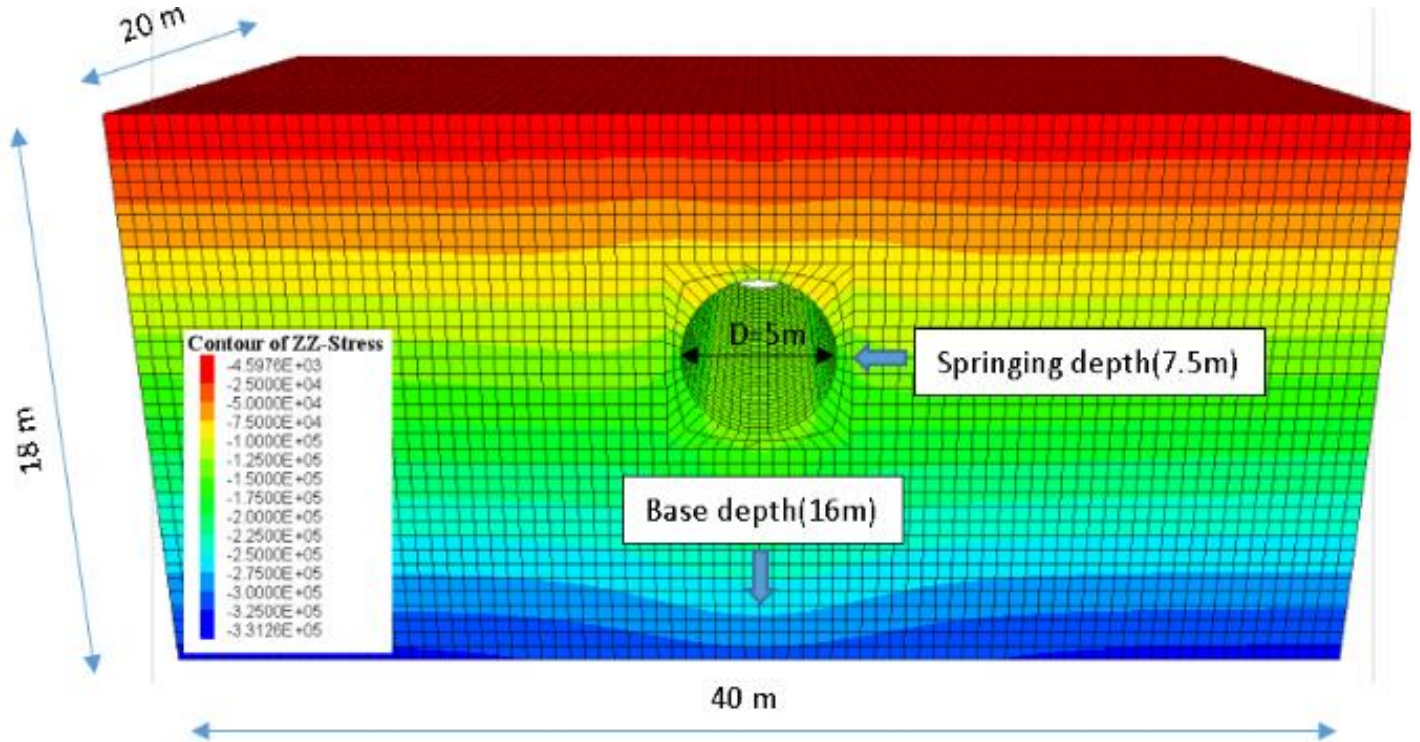

Fig. 6. The cross-sectional view of the model built by FLAC ${ }^{3 \mathrm{D}}$.

In the current analyses, 2D (FLAC) and 3D (FLAC3D) were conducted. The general meshing and layouts of these two models are shown, respectively in Figs. 5 and 6. The soil was simulated as an elastic model and the structure was simulated by linear structure element. From Fig. 7, it can be observed that the excess pore water pressure ratio is very close to the previous experimental results in both $2 \mathrm{D}$ and $3 \mathrm{D}$ numerical analyses at both depths in question $(7.5$ and $16 \mathrm{~m})$. 


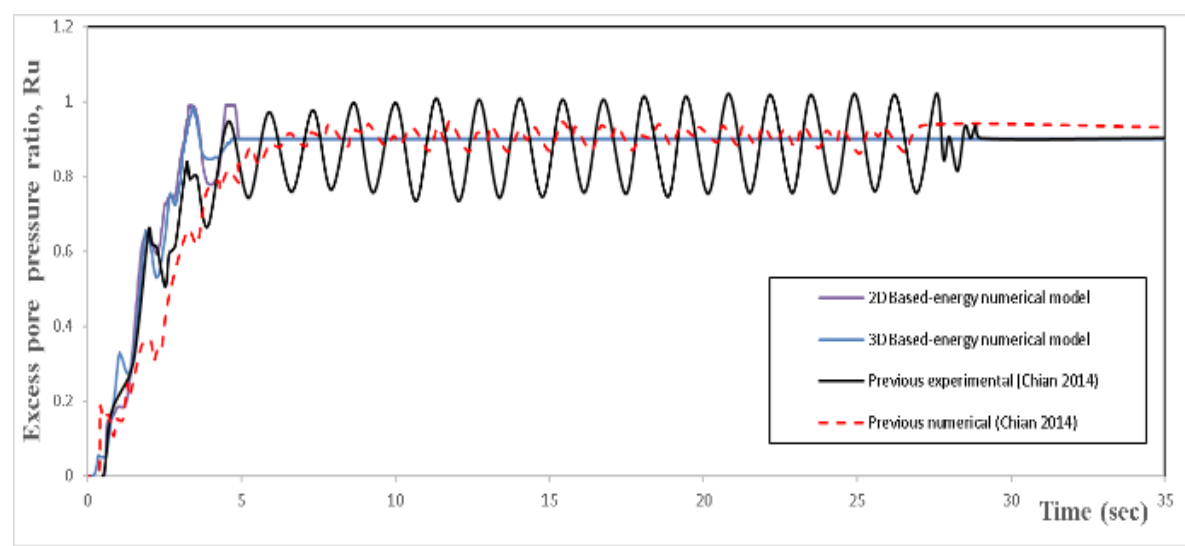

Fig. 7. Excess pore pressure ratio time history at the model base (16m depth).

\section{NUMERICAL RESULTS}

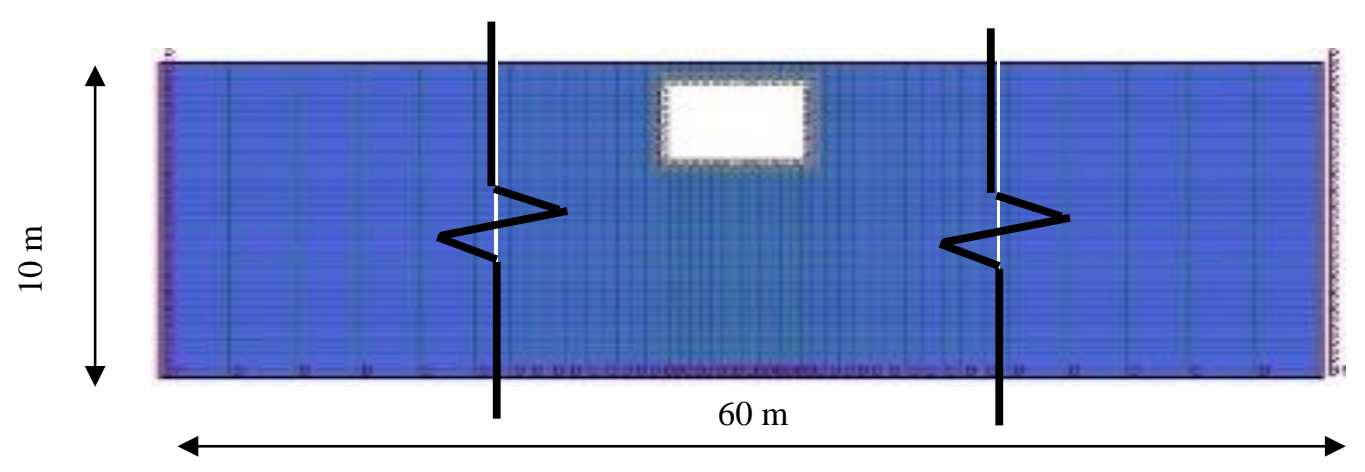

Fig. 8. The cross-sectional view of shallow tunnel model built by FLAC.

In this section, two-dimensional analyses of the sallow tunnel seismic behavior are performed by implementing the same FLAC model using the new constitutive soil model as shown in Fig. 8. The considered model consists of a sand layer of $60 \mathrm{~m}$ in width and from 5.0 to $20.0 \mathrm{~m}$ in depth. The tunnel is a rectangular structure of 3.75 widths and $2.75 \mathrm{~m}$ depth, is buried in the sand layer at a depth from 0.0 to $3.0 \mathrm{~m}$ from the ground surface. The water table level is assumed to be located from the ground surface to $3 \mathrm{~m}$ depth. Ottawa sand is used as the soil bed in the numerical models. The shear wave velocity of the used sand is various from 150 to $300 \mathrm{~m} / \mathrm{s}$. The material properties of Ottawa sand are presented in Table 1. The structure is assumed to be elastic material with Young modulus and the Poisson ratio of $25 \mathrm{GPa}$ and 0.25 [17-18].

The dimension of the zone elements was selected at $0.25 \times 0.25 \mathrm{~m}$ around the structure then the mesh size gradually increases whenever it goes outside. The peak ground acceleration (PGA) of the 2011 Great Japan earthquake has been chosen as a coefficient for expressing the intensity of the earthquake. The values of peak ground acceleration range from $0.125 \mathrm{~g}$ to $0.5 \mathrm{~g}$.

\subsection{Change the peak ground acceleration of the input earthquake}

In this part, four different seismic loads were used to study the effect of the seismic loading amplitude on the behavior of the underground structure. The maximum acceleration $\left(\mathrm{A}_{\max }\right)$ at the base of the model was selected to express the intensity of the earthquake. The motions used in this study were obtained from the 1988 Saguenay earthquake by modifying the amplitude of the accelerogram with values of $A_{\max }$ varying from $0.125 \mathrm{~g}$ to $0.5 \mathrm{~g}$. 


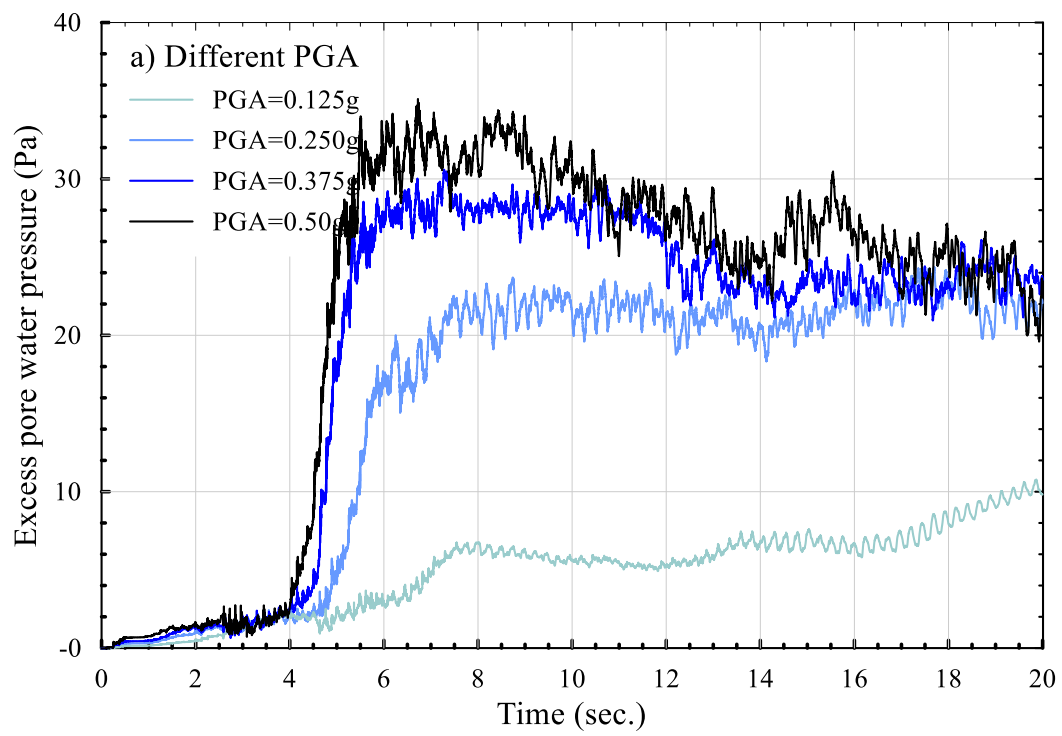

Fig. 9. Excess pore pressure time history under the tunnel with different PGA.

Fig. 9 shows the variation of the excess pore pressure at a depth of 4 meters from the surface of the deposit (below the underground structure). According to this figure, it can be seen that the excess pore pressure rises with increasing Peak Ground Acceleration (PGA) of the applied earthquake, which is represented by the maximum acceleration. The results show that earthquakes with a PGA of $0.25,0.375$, and $0.5 \mathrm{~g}$ induced local liquefaction of the soil below the structure unlike the other motion with a PGA of 0.125 where there was no liquefaction. We can also notice that earthquakes of $0.25,0.375$, and $0.5 \mathrm{~g}$ generate relatively the same pore pressures at a depth of $4 \mathrm{~m}$.

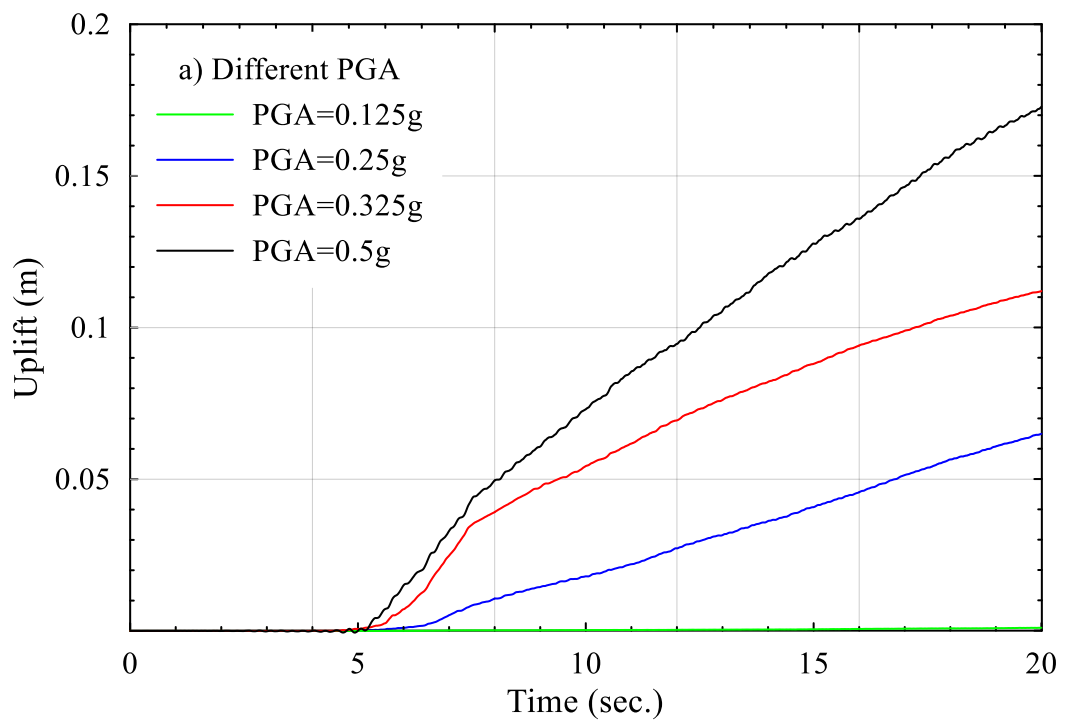

Fig. 10. Tunnel uplift displacement time history with different PGA.

Fig. 10 shows the variation of the tunnel uplift displacement due to an increase in earthquake PGA. According to this figure, numerical analyzes show an almost direct correlation between the PGA of the earthquake and the uplift of the structure. For example, an acceleration of $0.5 \mathrm{~g}$ produces an uplift of $18 \mathrm{~cm}$ at the end of the earthquake while an earthquake of $0.25 \mathrm{~g}$ produces $6 \mathrm{~cm}$ of uplift. While there is not uplift occurring in case of an earthquake of $0.125 \mathrm{~g}$. 


\subsection{Change the soil layer depth}

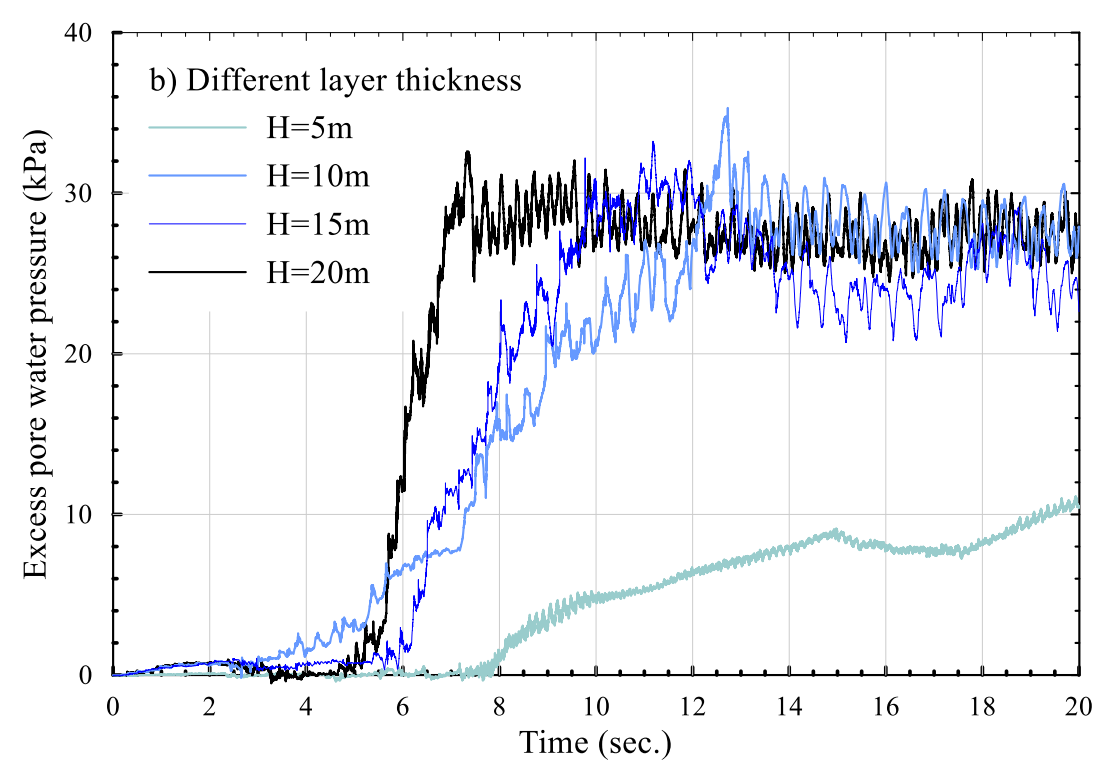

Fig. 11. Excess pore pressure time history under tunnel with different soil thickness.

In this part, the effect of the soil deposit thickness was examined on the tunnel seismic behavior. The level of the burial of the underground structure was still the same. The thickness of the deposit varies from $5.0 \mathrm{~m}$ to 25.0 m. Fig. 11 shows the variation of the excess pore pressure below the bottom of the tunnel at a depth of $4 \mathrm{~m}$. According to this figure, the excess pore water pressure increases significantly up to about 6 seconds to reach an approximately constant value. Besides, the excess pore pressure faster increases with increasing deposit thickness but reaches similar values later. While, at thicknesses less than $10 \mathrm{~m}$, the pore pressure increases less rapidly, and no complete liquefaction had occurred.

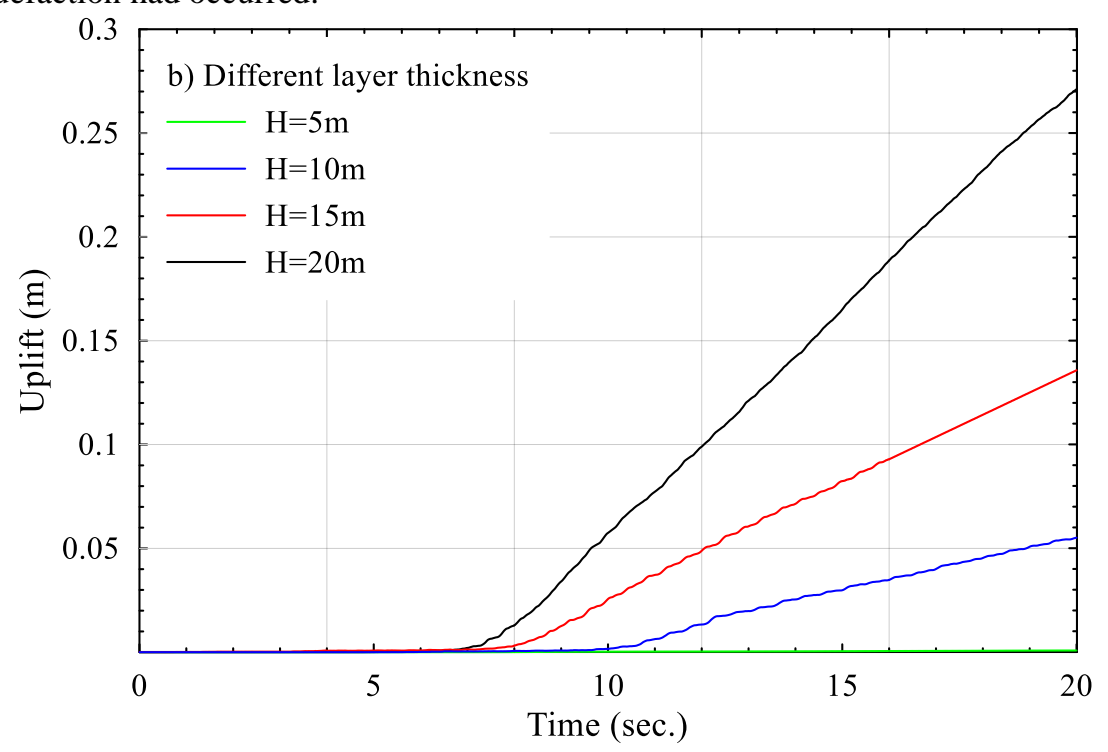

Fig. 12. Tunnel uplift history with different soil thickness.

Fig. 12 shows the variation in the uplift of the underground structure. According to this figure, the uplift of the structure increases with the increase in the thickness of the soil deposit. However, in the case of five-meter soil layer thickness, there is no tunnel uplift occurred. 


\subsection{Change the structure depth.}

In this step, four different depths of the underground tunnel were chosen to study the influence of the burial depth. The upper level of the underground structure was chosen as the study variable. The upper level of the tunnel varies from $0.0 \mathrm{~m}$ to $3.0 \mathrm{~m}$ from the ground surface.

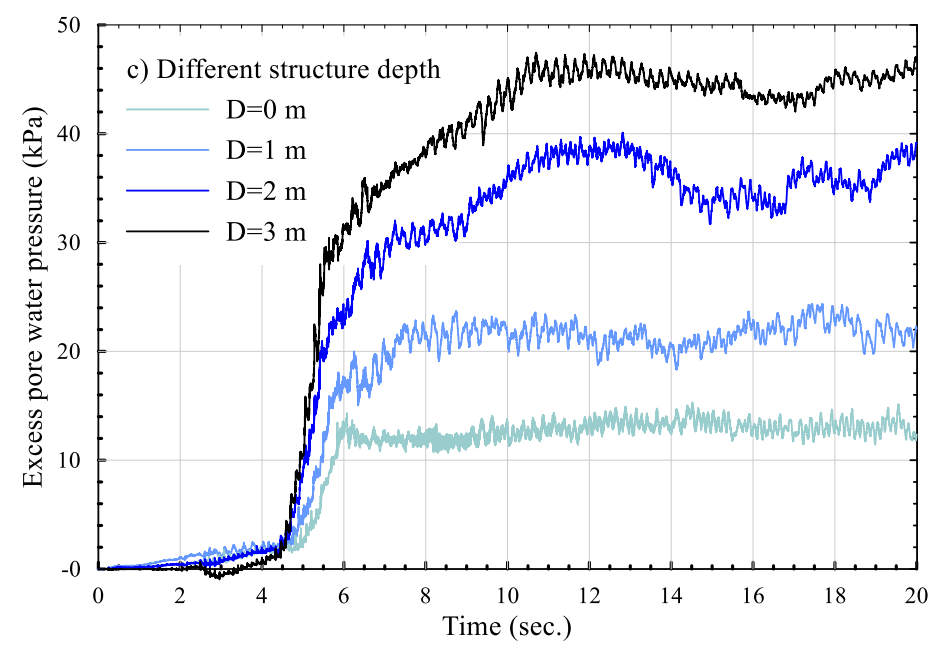

Fig. 13. Excess pore pressure time history under tunnel with different tunnel depths.

Fig. 13 shows the variation of the pore pressure at a point located under the bottom of the buried structure. According to this figure, the excess pore pressure increases significantly to reach an approximately constant value. In addition, it can be seen that the excess pore pressure increases with the increasing burial depth of the underground structure. This is related to the increase in the effective stress of the soil below the structure because the deeper the structure, the higher the stress.

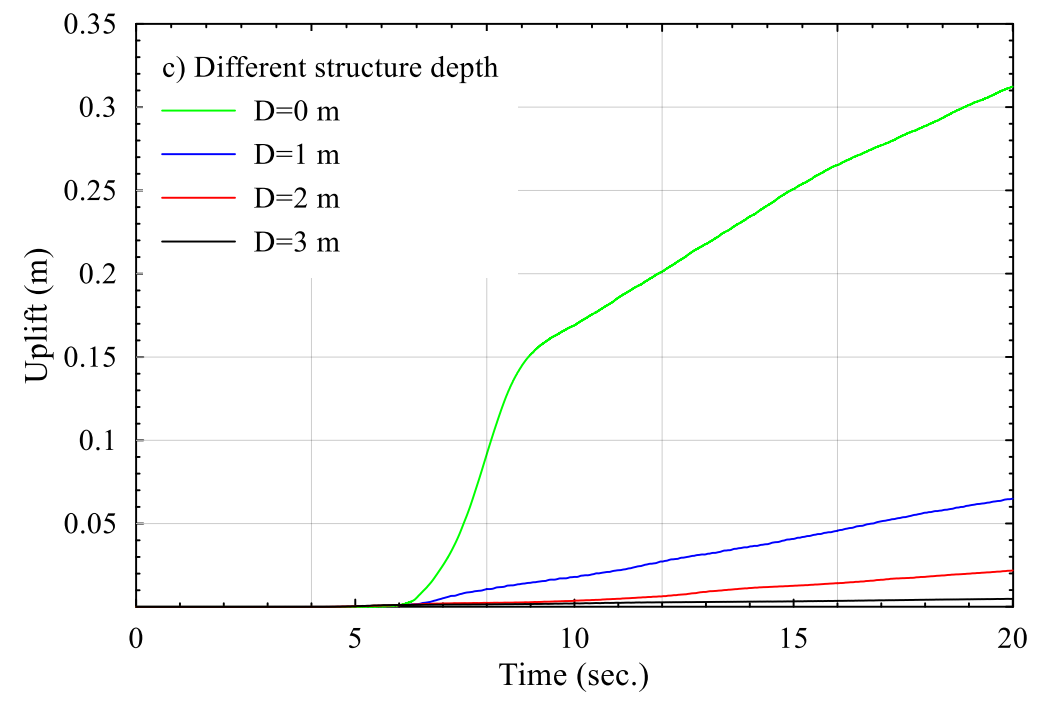

Fig. 14. Tunnel uplifts displacement time history with different burial depths.

Fig. 14 shows the variation in the vertical displacement of the buried tunnel. According to this figure, it can be seen that the uplift of the buried structure increased with the approach of the underground structure to the ground surface. Although the pressure of the pore water under the structure decreases each time the buried structure is shallower, the uplift of the buried structure increases due to the less weight of soil above it. 


\subsection{Different soil stiffness}

In this study, four sandy soils with different stiffness (from loose to dense) were used to study the influence of shear resistance of foundation soils on the seismic behavior of the underground tunnel. The shear wave velocity of the soil $\left(\mathrm{v}_{\mathrm{s}}\right)$ was chosen as a parameter to express the shear stiffness of the soil. Indeed, the speed of the shear waves is directly related to the shear modulus $\left(G_{\max }=\gamma^{*} \mathrm{v}_{s}^{2}\right)$. The values of the shear wave velocity used vary between $150 \mathrm{~m} / \mathrm{s}$ to $300 \mathrm{~m} / \mathrm{s}$ by increasing $50 \mathrm{~m} / \mathrm{s}$ every once.

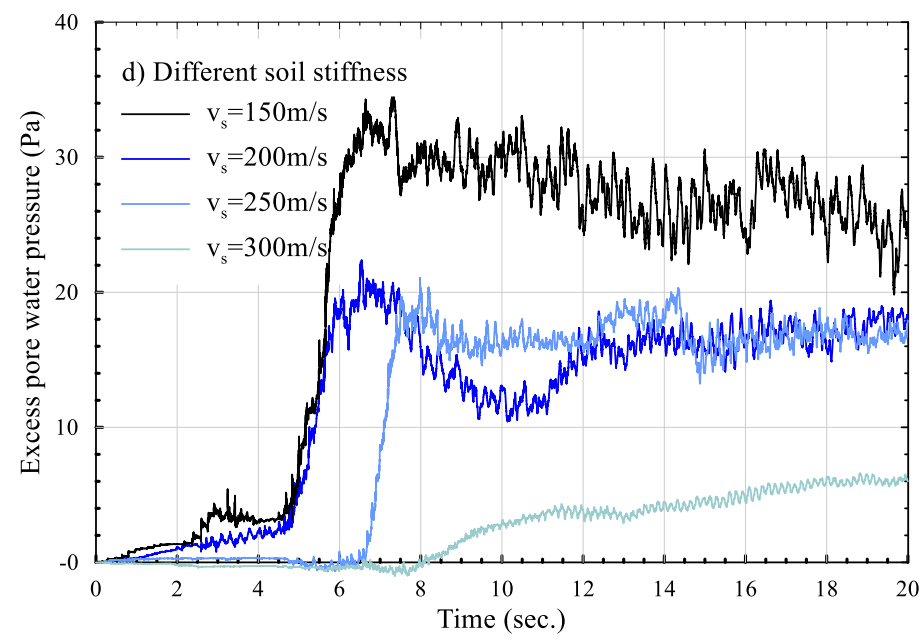

Fig. 15. Excess pore pressure time history under the tunnel for different soil stiffness.

Fig. 15 shows the variation of the excess pore pressure at an element immediately below the underground structure ( $4 \mathrm{~m}$ depth). According to this figure, the excess pore pressure increases significantly to reach an approximately constant value. In addition, it can be seen that the pore pressures increase with the decrease in the stiffness of the soil, which is represented in this case by the speed of the shear wave (Vs).

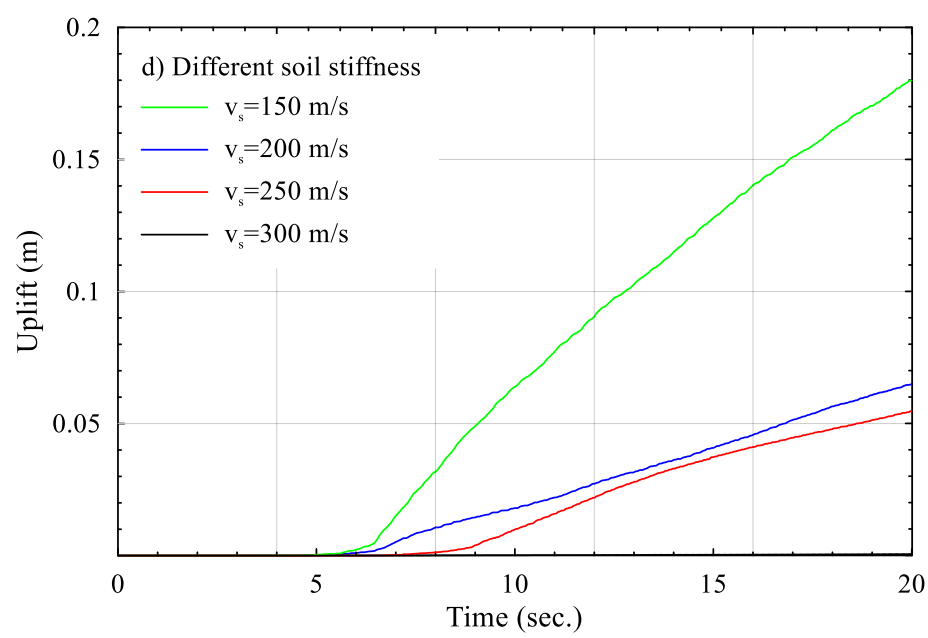

Fig. 16. Tunnel uplifts displacement time history with different soil stiffness.

Fig. 16 shows the variation in the tunnel uplift. According to this figure, the numerical analyzes reveal that the generation of pore pressure induced a lifting of the structure. Thus, it is possible to see that the uplift of the underground structure increases with the decrease in the rigidity of the soil $\left(\mathrm{G}_{\max }\right)$. Also, the movements do not 
stop at the end of the analysis since the excess pore pressure in the soils is not yet dissipated. This means that one should expect larger displacements than those observed at the end of the seismic event.

\subsection{Different groundwater level}

In this part of the study, the groundwater level at four different depths was chosen to study its effect on the behavior of the underground structure. The underground tunnel burial depth is the same in all cases. The groundwater level varies from $0.0 \mathrm{~m}$ to $4.0 \mathrm{~m}$ above the ground surface.

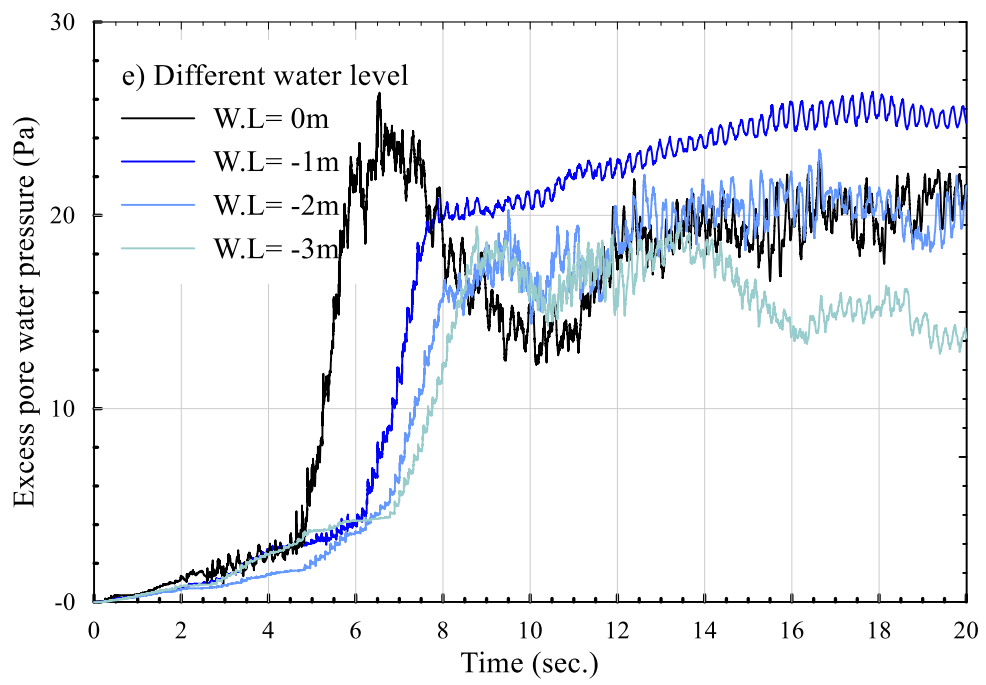

Fig. 17. Excess pore pressure time history under the tunnel at different groundwater levels

Fig. 17 shows the variation of the pore pressure under the underground structure at a depth of $4.0 \mathrm{~m}$. According to this figure, the pore pressure increases slowly at the start of the earthquake, due to the low value of the seismic load, then more rapidly around 5.0 to 8.0 seconds depending on the level of the water table. However, the pore pressure reached practically the same value for the four cases examined at the end of the earthquake.

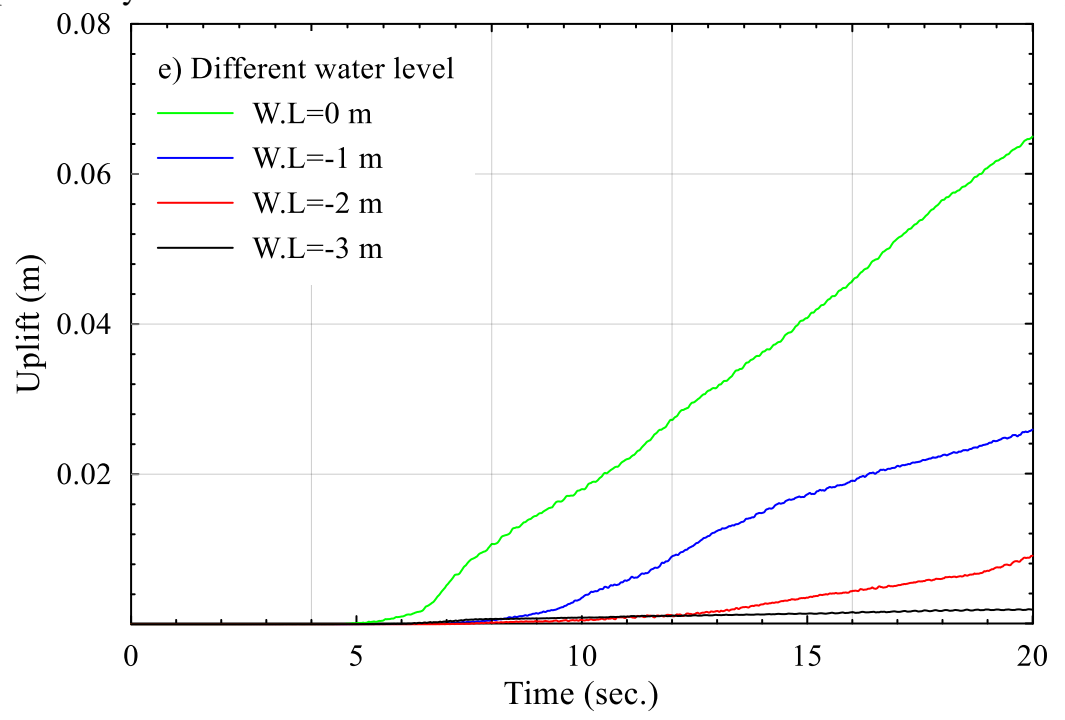

Fig. 18. Tunnel uplifts displacement time history with different groundwater levels. 
Fig. 18 shows the variation in the uplift of the underground structure. According to this figure, it can be seen that the uplift is low at the start of the earthquake due to the low value of the seismic load and then increases with increasing acceleration. However, the final uplift decreases with an increasing depth of the groundwater table. It is important to note that the uplift of the underground structure is practically zero if the level of the water table is located under the tunnel base.

\section{CONCLUSION}

In order to examine the applicability/performance of the energy-based model in studying the seismic behavior of underground structures in liquefaction soils, a set of dynamic simulations on liquefied sand samples have been conducted using the energy-based model and previous experimental and numerical models. The experimental data is then used to calibrate the energy-based concept following the work of Chain et al. [15] for pore pressure generation modeling. As a part of this study, ground response analyses of a tunnel are done using the computer code, FLAC adopting the energy-based model.

1. Soil liquefaction is one of the most important reasons that lead to the failure of the tunnel.

2. Energy-based model is very similar to experimental results. This similarity confirms the accuracy and reliability of the energy-based model adopted in FLAC.

3. The underground tunnel starts to uplift when the soil is fully liquefied.

4. The rise of the groundwater level, the low structure buried depth, small soil shear wave velocity, large soil layer thickness, and increase earthquake PGA led to an increase in the possibility of liquefaction occurrence, therefore, the tunnel can float.

\section{ACKNOWLEDGMENT}

The authors would like to thank Prof. Mourad Karray from Sherbrooke University, Dr. Eng. Mohamed Chekired from Hydro-Québec, and Dr. Mahmoud Nasser Hussien, from John Wood Group for their support.

\section{REFERENCES}

[1] Q. Yue and J. Li, "Seismic analysis of utility tunnel considering wave passage effect," Proceedings of the $4^{\text {th }}$ International Conference on Earthquake Geotechnical Engineering, Thessaloniki, Greece, 2007.

[2] S. C. Chian and K.Tokimatsu, "Floatation of Underground Structures during the Mw9.0 Tōhoku Earthquake of $11^{\text {th }}$ March 2011," Proceedings of the $15^{\text {th }}$ World Conference on Earthquake Engineering, Lisbon, Portugal, 2012.

[3] M. Yoshida et al., "Experimental study on mitigation of liquefaction-induced flotation of sewerage manhole by using permeable recycled materials packed in sandbags," Proceedings of the $14^{\text {th }}$ World Conference on Earthquake Engineering, Beijing, China, 2008.

[4] R. Des-Roches et al., "Overview of the 2010 Haiti earthquake," Earthquake Spectra, vol. 27, no. S1, pp. S1S21, 2011.

[5] S. Potter et al., "An overview of the impacts of the 2010-2011 Canterbury earthquakes," International Journal of Disaster Risk Reduction, vol. 14, pp. 6-14, 2015.

[6] RP. Orense "Soil liquefaction during the 2010 Darfield and 1990 Luzon Earthquakes: A comparative study," Proceeding of the $9^{\text {th }}$ Pacific Conference on Earthquake Engineering Building an Earthquake-Resilient Society, 14-16 April, Auckland, New Zealand, 2011.

[7] A. Yamaguchi et al., "Liquefaction in Tohoku district during the 2011 off the pacific coast of Tohoku earthquake," Soils and Foundations, vol. 52, no. 5, pp. 811-829, 2012.

[8] G. Kang et al., "Seismic simulation of liquefaction-induced uplift behavior of a hollow cylinder structure buried in shallow ground," Soil Dynamics and Earthquake Engineering, vol. 64, pp. 85-94, 2014.

[9] A. A. Javadi et al., "Evaluation of liquefaction-induced lateral displacements using genetic programming," Computers and Geotechnics, vol. 33, no. 4/5, pp. 222-233, 2006.

[10] R. A. Green, "Energy-based evaluation and remediation of liquefiable soils," Ph.D. thesis, Civil Engineering Department, Virginia Polytechnical Institute and State University, Blacksburg, VA, 2001. 
[11] C. Polito et al., "Effect of load shape on relationship between dissipated energy and residual excess pore pressure generation in cyclic triaxial tests," Canadian Geotechnical Journal, vol. 50, no. 11, pp. 1118-1128, 2013.

[12] J. Sunitsakul, "The Cyclic Behavior of Silt Soils, Dissertation submitted in partial fulfillment of the Doctor of Philosophy in Civil Engineering," Department of Civil, Construction and Environmental Engineering, Oregon State University, 2004.

[13] M. Karray et al., "Failure mechanisms of underground structures during earthquake: an overview," $68^{\text {th }}$ Canadian Geotechnical Conference and $7^{\text {th }}$ Canadian Permafrost Conference (Geo-Québec), Québec, Canada, 2015.

[14] Itasca Consulting Group, "FLAC ${ }^{3 \mathrm{D}}$ : Fast lagrangian analysis of continua in 3-dimensions 5.01 manual," Itasca, Minneapolis, 2013.

[15] S. C. Chian et al., "Soil liquefaction-induced uplift of underground structures: physical and numerical modeling," Journal of Geotechnical and Geoenvironmental Engineering, vol. 140, no. 10, pp. 04014057, 2014.

[16] Z. Wang et al., "A full coupled numerical analysis approach for buried structures subjected to subsurface blast," Computers and Structures, vol 83, pp. 339-356, 2005.

[17] F. Khoshnoudian, and I. Shahrour "Numerical Analysis of the Seismic Behavior of Tunnels Constructed in Liquefiable Soils," Soils and Foundations, vol 42, no. 6, pp. 1-8, 2002.

[18] J. Zhou et al., "Micro-and macro-observations of liquefaction of saturated sand around buried structures in centrifuge shaking table tests," Soil Dynamics and Earthquake Engineering, vol. 72, pp. 1-11, May 2015. 